\title{
El Paraíso terrenal en la América del siglo XVII: Antonio de León Pinelo y Simão de Vasconcellos ${ }^{1}$.
}

\section{The Earthly Paradise in the America of XVII Century: Antonio de León Pinelo and Simão de Vasconcellos.}

\section{Resumen}

El presente trabajo analiza la obra de dos autores del siglo XVII que sitúan el Paraíso terrenal en el continente americano: El Paraíso en el Nuevo Mundo del bibliófilo y jurista español Antonio de León Pinelo y Das noticias antecedentes, curiosas e necessarias das cousas do Brasil del jesuita portugués Simão de Vasconcellos. El análisis comprende una revisión de los argumentos que ambos autores desarrollan con el fin de situar el jardín del Edén en la Amazonía. Mediante la cita a autoridades y la edenización del territorio, ambos dan cuenta de una perspectiva de enunciación situada en América, desde la que sostienen una visión identitaria del pensamiento periférico.

Palabras claves Antonio de León Pinelo, Simão de Vasconcellos, Paraíso Terrenal, Pensamiento periférico.

\begin{abstract}
This paper analyzes the works of two authors of the XVII century which locate the Earthly Paradise in the American continent: El Paraíso en el Nuevo Mundo by the Spanish lawyer and bibliophile Antonio de León Pinelo and Das noticias antecedentes, curiosas e necessarias das cousas do Brasil by the Portuguese Jesuit priest Simão de Vasconcellos. The analysis is a

${ }^{1}$ El presente artículo forma parte de la tesis "El Paraíso Terrenal en América. La función política del mito del Paraíso en la América colonial. Siglos XVI y XVII", dirigida por el Dr. Nelson Osorio Tejeda y escrita para optar al grado de Doctor en Estudios Americanos por el Instituto de Estudios Avanzados de la Universidad de Santiago de Chile (IDEA-USACH).
\end{abstract}


review of the arguments which both authors develop for the purposes of locatingthe Garden of Eden in the Amazon. Based on the citation of eminent authorities and the edenization of the territory, both show an enunciation perspective positioned in America, from which they argue an identitary vision of the peripheral thought.

Keywords Antonio de León Pinelo, Simão de Vasconcellos, Earthly Paradise, Peripheral Thought.

El siglo XVII es un periodo de asentamiento del orden colonial, en que el conquistador, figura central en los tiempos de la invasión y ocupación, dio paso al estudioso y al misionero. Si bien este siglo significa la decadencia del poderío español en Europa, en América la lucha de las otras potencias europeas por el territorio se intensifica sin lograr un verdadero daño al poder ibérico. El paso desde el expansionismo hacia la consolidación de las estructuras de dominación ibéricas no marca la decadencia imperial, sólo significa que la ocupación ya se encuentra asentada.

Culturalmente, en este periodo surgen las primeras voces del mestizaje, autores que presentan la voz indígena como Guaman Poma de Ayala o el Inca Garcilaso de la Vega. Aparecen las primeras redes de escritores americanos como la Academia Antártica al alero de Diego Mexía. Al mismo tiempo, en Nueva España, emergen voces como sor Juana Inés de la Cruz y Carlos de Sigüenza y Góngora. El siglo XVII es, bajo el signo del llamado Barroco de Indias, cuando eclosiona la capacidad creativa a lo largo de América, aunque no llega a gestarse un discurso emancipatorio.

En este periodo de creación se inscriben las obras de Antonio de León Pinelo en el Perú y de Simão de Vasconcellos en Brasil. Enmarcadas en el Barroco y la Contrarreforma, ambas obras enunciarán una vuelta a ciertos temas propios de la discusión medieval que tenían como centro los misterios de la Biblia. En el caso que nos importa acá, recuperan la discusión sobre el lugar en que se plantó el jardín del Edén; rescatando, además, las versiones que lo situaban en América. 
Estableciendo como problema de investigación la recurrencia del mito edénico en el continente americano durante los siglos XVI y XVII, el presente trabajo desarrolla la hipótesis de que la ubicación del Paraíso en América tendría una intención política que, en el siglo XVII, buscaría reivindicar el continente frente a Europa y su historia, situación que se condice con los motivos del pensamiento periférico. Dicha hipótesis se desarrolla mediante un estudio documental, siguiendo los lineamientos de la llamada historia cultural.

Así las cosas, Eduardo Devés (2014) plantea que el pensamiento de las periferias surge sólo en relación con la dominación de las metrópolis. Define dicho pensamiento periférico "como aquel emergido en el seno de comunidades impactadas por la, más o menos cercana, presencia del nuevo centro, que trastorna la tradicional comprensión del mundo que poseían" (Devés 33). Así, hay dos formas de relacionarse con el centro: imitarlo o diferenciarse. Los grupos que plantean la necesidad de imitar al centro, son llamados centralitarios; los otros, identitarios. Aunque Devés sitúa el origen del pensamiento periférico en el siglo XVIII, no niega la existencia de antecedentes y proto-manifestaciones, en las que circunscribiríamos a León Pinelo y a Vasconcellos, ya que, si bien no llegan a forjar un pensamiento emancipador frente a Europa, sí conciben el principal motivo periférico, esto es, “defender, reivindicar, afirmar alguna dimensión de su realidad, en primer lugar respecto de argumentaciones denigrantes provenientes desde el centro" (Devés 59).

Tanto Vasconcellos como León Pinelo señalan que América es un territorio distinto, con condiciones originales e irrepetibles, con sus propias formas y una naturaleza extraña. Esto sustenta el principal motivo identitario del pensamiento periférico:

Los motivos identitarios se articulan sobre la base de la idea que la (propia) periferia no es inferior sino diferente al centro, que muchas veces es incluso superior y que hasta podría salvar al centro. Nociones como que la cultura, y particularmente la espiritualidad, de la propia 
región (no de toda la periferia) es superior a la del centro, que la región ha realizado grandes aportes a la humanidad, que la cultura de la propia región es más antigua e incluso es fuente de la del centro (Devés 60).

\section{II}

En 1656, Antonio de León Pinelo, bibliófilo español y oidor del Rey en Perú, imprime el aparato -es decir, la portada y los índices- de El Paraíso en el Nuevo Mundo. Comentario apologético, historia natural y peregrina de las Yndias Occidentales yslas y tierra firme del Mar Occeano, escrito entre 1645 y 1650 e inédito hasta su publicación en 1943 por el historiador peruano Raúl Porras Barrenechea.

La obra inicia con el propósito que la guiará: "Yntento es y Qüestión fundamental deste Comentario investigar el Sitio y colegir el lugar que tuvo en su creación el Paraiso Terrenal: y si fué ó pudo ser en el Nuevo Mundo, que llamamos Yndias Occidentales, ó en alguna de sus Provincias" (León Pinelo, El Paraíso... I: 1).

En el segundo libro se sitúa al Paraíso en América. No propone nada distinto a lo ya han dicho otros: "Nuestro autor no presenta un pensamiento original, por peregrina que sea su tesis, ya que pertenece a un mundo de cultura jerarquizada y basada en la autorictas [sic], el de la España católica de la contrarreforma, donde reina la teología de la segunda escolástica" (Pellicer 30). Sea como fuere, nuestro autor tiene dos pilares argumentales para situar el Paraíso en el continente: a) el criterio de autoridad; y b) las condiciones del territorio.

León Pinelo cita un sinfín de textos. Para sostener su tesis se basa en los escritos de Efrén y de Moshe Bar-Kepha, quienes proponen que el Paraíso podría encontrarse en un continente distinto a los conocidos. Efrén, es doctor de la Iglesia, creador de dogmas dentro del canon católico, nacido en Mesopotamia durante el siglo IV. Según Rosa Pellicer, habría percibido el Edén en un sentido místico y espiritual, aunque sus Himnos sobre el Paraíso lo ubican 
CATEDRAL TomadA: Revista de crítica literaria latinoamericana / Journal of Latin American Literary Criticism

El Paraíso terrenal en la América del siglo XVII: Antonio de León Pinelo y Simão de Vasconcellos.

geográficamente: "En ese halo que se forma / alrededor de la luna / veamos el Paraíso: / así también él rodea / mar y tierra, / que están como dentro de él" (Pellicer 32) ${ }^{2}$. Con base en estos versos, Bar-Kephas arguye que otro podría ser el continente del Paraíso. Bar-Kephas fue un escritor y teólogo sirio del siglo IX, seguidor de Efrén, llegó a ser Obispo en tres ciudades sirias. Porras Barrenechea describe la idea del sirio respecto al Paraíso: "El Bar-Cefas [...] sostiene que el Paraíso fue tierra diferente de la occidental en naturaleza y en calidad, que estaba en medio del mar, rodeada de montes inaccesibles, en aguas no navegadas por ningún hombre y que el Océano primero y el Paraíso después de éste, rodeaban como dos círculos concéntricos el mundo conocido" (Porras Barrenechea, XXXIII).

León Pinelo adopta esta opinión y la respalda arguyendo que antes del diluvio la humanidad sabía dónde se encontraba el Edén (El Paraíso... I: 120). Con esto, León Pinelo concluye que el Paraíso se encuentra fuera de las tierras conocidas durante la Edad Media, por lo que su paso hacia América resulta casi lógico. Entonces: "el Paraiso Terrenal estuvo en el Continente del Nuevo Mundo; porque en él y no en otra parte del Orbe todo se puede verificar la Opinion de San Efren" (El Paraíso... I: 126).

Para establecerlo definitivamente en América, el autor recurre a viajeros y autoridades que ya han sostenido esta idea:

Esta pues nueva aunque antiquisima Opinion de que el Paraiso haya sido en el Nuevo Mundo, sin explicarla ni aplicarla a la de san Efren, han tocado y referido Autores graves. El primero que tuvo este pensamiento fue el primer Descubridor del Nuevo Mundo el Almirante Don Christoval Colon [...]. Hicieron mención desta Opinion, Francisco Lopez

\footnotetext{
${ }^{2}$ Rosa Pellicer consulta los textos de san Efrén en la traducción que hace el arzobispo de Granada, Francisco Martínez Fernández, y que se encontraban disponibles en el sitio web www.sanefren.es. Lamentablemente, dicho sitio ya no se encuentra activo, por lo tanto, nos vemos en la necesidad de citar el texto de Pellicer.
} 
de Gomara, Martin del Rio, Antonio de Herrera, Doctor Don Juan de Solorzano, el P. Josef de Acosta, Fray Tomas de Maluenda, Laurencio Beierlinc, ibi alii in America Cornelio Jansenio, Obispo Iprense, Leonardo Mario, Cornelio a Lapide, y don Fernando de Montesinos que en la dedicación del Auto de la Fe celebrado en Lima el año de seiscientos y quarenta, empieza así: "Dos Autos de la Fe los mayores se han celebrado en la America. El uno hizo Dios primer Ynquisidor contra la apostasía de Adan y Eva, en el Theatro del Paraíso”, y se remite a la Historia del Paytiti, que aun no ha salido a la luz. Fr. Claudio de Abevile Religioso Capuchino [...] y el P. Nicolao Abramo (El Paraíso... I: 133134).

El Paraíso en el continente americano comienza, tal como indica León Pinelo, con Cristóbal Colón quien, en el Diario del tercer viaje (1498-1500), ubica el Paraíso en América por tres condiciones: a) la cantidad de agua dulce que existía en el interior del mar, en la desembocadura del Orinoco (Colón 372); b) la templanza del clima, en que no existían inviernos demasiado fríos ni veranos demasiado cálidos (375); y c) los cambios en la ubicación de la estrella del norte, lo que hace suponer a Colón que se encuentra en una loma en el mar (375-376). Así, el Edén estaría sobre una montaña en el mar, por lo que el mundo no sería redondo sino que tendría forma de pera. (377).

Francisco López de Gómara (1511-1566), eclesiástico e historiador español cercano a Hernán Cortés, en su Historia general de las Indias comenta la hipótesis de Colón sin entregar su opinión sobre el sitio del Paraíso. En su descripción del viaje colombino otorga sentido a la teoría de Colón por las condiciones en que se encontraba: "Tenía tanta gana y necesidad de verse en tierra, que se le antojó Paria paraíso; y ¿quién no tenía por paraíso tal tierra, saliendo de tan trabajoso mar?" (128). Finalmente, se desliga de esta opinión indicando que nadie ha situado con exactitud el Paraíso, y que hay variadas teorías sobre su ubicación. 
CATEDRAL Tomada: Revista de crítica literaria latinoamericana / Journal of Latin American Literary Criticism

El Paraíso terrenal en la América del siglo XVII: Antonio de León Pinelo y Simão de Vasconcellos.

Martín del Río o Delrio (1551-1608), sacerdote de los Países Bajos que escribe Adagalia sacra veteris et novi testamenti [1614], en el Adagio número 779 -y no en el 799 como indica León Pinelo en nota al pie- escribe que las doctrinas de Efrén y Bar-Kephas sitúan el Paraíso en una tierra distinta a los continentes conocidos en la Edad Media. Sin embargo, no cree que sea América el espacio en que se sitúa (Delrio 378).

Antonio de Herrera (1549-1626), Cronista Mayor de las Indias durante los reinados de Felipe II y III, autor de la Historia general de los hechos de los castellanos en las Islas y Tierra Firme del mar Océano que llaman Indias Occidentales, las que fueron publicadas en cuatro tomos entre 1601 y 1615. Al igual que López de Gómara, Antonio de Herrera sólo refiere al viaje de Colón. En el capítulo XII del libro III de la Primera Década, comenta la idea de Colón sobre el Paraíso y las condiciones que lo llevan a pensar que se encontraba cerca del Edén, sin embargo, señala que es de un acto de imaginación del Almirante (Herrera 84-85).

Juan de Solórzano (1575-1655), jurista español, amigo y mentor de León Pinelo, en su texto De Indiarum iure -publicado en dos partes en 1629 y 1639-, integra una descripción de la naturaleza americana. En el capítulo séptimo del primer libro, Solórzano señala que la naturaleza y las condiciones de las Indias llevan a pensar que se trata del Paraíso Terrenal, aunque "es imposible admitirlo sin ligereza" (245), puesto que Dios quiso que permaneciese oculto.

Joseph de Acosta (1540-1600), historiador y naturalista jesuita de gran importancia para las letras y la historiografía de Nuestra América, señala en su Historia natural y moral de las Indias [1590]: "Si guiaran su opinión por aquí, los que dicen que el Paraíso Terrenal está debajo de la Equinocial, aun parece que llevaran algún camino, no porque me determine yo a que está allí el Paraíso de los Deleites que dice la Escritura, pues sería temeridad afirmar eso por cosa cierta" (Acosta 95). Continúa con una descripción edenizada del territorio americano, pero no afirma que el Edén se haya encontrado en América. 
Fray Tomás de Maluenda (1566-1628), sacerdote dominico español, expone en su De paradiso volvptatis quem Scriptvra Sacra Genesis secvndo et tertio capite describit [1605], que existe la opinión de que san Efrén intuyó las tierras americanas y que situó el Paraíso en ese lugar. Sin embargo, rechaza esta idea argumentando que nadie en su sano juicio la admitiría, que es una lectura demasiado liberal de las Escrituras $\mathrm{y}$, entre otras cosas, que no hay ningún testimonio en la Biblia ni en los padres de la Iglesia que permita suponer que América contuvo al Paraíso (Maluenda 24).

Laurentio Beyerlinck (1578-1627), teólogo y escritor religioso belga, es conocido por su obra Magnum Theatrum Vitae Humanae de 1631. Una enciclopedia que recoge temas de distinta importancia. Lamentablemente, no hemos podido acceder al tomo séptimo de esta obra que es el citado por León Pinelo.

Cornelio Jansenio (1585-1638), obispo de la ciudad de Ypres - de ahí la categoría de Obispo Iprense-, fundador del movimiento jansenista. León Pinelo cita sus Comentarios al Pentateuco, texto al que no hemos podido acceder. Tampoco hemos podido obtener información acerca de Leonardo Mario.

Cornelio a Lapide (1567-1637), sacerdote jesuita y exégeta flamenco, su obra más conocida son los Comentarii in Sacram Scripturam, en los que comentó casi toda la Biblia. En el primer tomo de esta obra, dedicado al Génesis, escribe que Efrén y Bar-Kepha indican que el Paraíso se encontraba en otro continente, mientras que el Darocense lo sitúa en Palestina, a la vez que otros autores lo ubican en la isla Taprobana y otros en América. Sin embargo, señala que los cuatros ríos del Paraíso no están ni en Palestina, ni en Taprobana, ni en América (Lapide 71).

Fernando de Montesinos (¿?-1652), historiador y clérigo español. El año 1639, el Tribunal de la Inquisición le solicita escribir la relación del Auto de fe realizado en Lima ese año, uno de los más grandes de la historia colonial americana (Medina 144). Escribe su Avto de fe celebrado en Lima a 23 de enero de 1639. Al Tribunal del Santo Oficio de la Inquisicion de los Reynos del Peru, 
Chile, Paraguay y Tucuman. En la dedicatoria de la obra, hace una comparación entre los dos mayores Autos de fe en América: el que realizó Dios en el Paraíso al inicio de los tiempos y el de Lima en 1639, teniendo ambos resultados similares, ya que, si en el primero se expulsa a Adán y Eva del Paraíso, en el de 1639 se expulsa a los herejes de todas las Indias. Respecto a la ubicación del Edén en América, señala que el tema es tratado con mayor profundidad en su obra Historia del Paytiti, la que permanece inédita hasta el día de hoy (Montesinos).

Claude d'Abbeville (¿?-1632), franciscano francés que fue enviado como misionero a la Amazonía. Llega en una misión enviada en 1611 por María de Mèdici, regenta del trono francés. En 1614 publica su Histoire de la mission des pères Capucins en l'isle de Maragnan et terres circonvoisins. Lamentablemente no hemos podido tener acceso a esta obra.

Finalmente, Nicolas Abram o Nicolao Abramo (1589-1655) publica en Paris, en 1648 Pharus Veteris Testamenti, sive sacrarum quaestionum libri XV. Quibus accesserunt ejusdem auctoris de veritate et mendacio libri IV, que son sus comentarios sobre el Viejo Testamento. Dedica el segundo libro a las características y ubicación del Edén. Cita las referencias de Efrén y de Bar-Kepha pero no sitúa el Paraíso en América, sino que plantea que hay algunas opiniones que lo ubican en el continente (Abramo 43).

Aunque León Pinelo exhibe los distintos textos bajo una forzada unidad discursiva, en realidad su argumentación es sumamente variada y con distintos entusiasmos a la hora de situar al Paraíso en América, la mayoría incluso niega la posibilidad. León Pinelo entrega una gran lista de autores que mencionan la tesis del Paraíso en América, sin detenerse a considerar si apoyan o rechazan la idea.

Dicha actitud puede ser comprendida como una manera de resguardar la vida frente al Tribunal del Santo Oficio de la Inquisición. Si bien León Pinelo es un magistrado supernumerario de la sala de justicia de la Casa de Contratación, su ascendencia es judía, por lo que es sospechoso de ser judaizante. Su abuelo y algunos miembros de su familia fueron condenados a muerte por la Inquisición, e incluso su padre y hermano fueron sometidos a interrogatorios (Medina 154-155). 
Porras Barrenechea señala que "toda proposición insólita puede llevar un germen de herejía, más si proviene de un árbol sospechoso como el de Pinelo" (XXXII). Con los testimonios de Efrén y de Bar-Kepha, respaldados por otros autores católicos y, finalmente, con el sustento de los autores que situarían al Paraíso en América, León Pinelo construye un aparataje crítico que le ayuda a resguardarse teóricamente frente a los ataques que pudiera recibir.

El segundo eje de la argumentación tiene relación con las características propias del Paraíso, es decir, un territorio en donde siempre es primavera, la naturaleza es abundante, que se confunde con el relato de la Edad de Oro, etcétera. León Pinelo no cambia las versiones que sustentan lo paradisiaco. Antes, reconoce estas cualidades y las señala como uno de los elementos fundamentales a la hora de situar el jardín del Edén:

Es el sitio de la Equinoccial donde quiera que se condidere el mas calificado y preeminente por naturaleza de todos los del Mundo. En el no se mudan los tiempos, son siempre iguales los días y las noches ellas con la frescura que basta, ellos con el calor que conserba el perpetuo berdor de las Plantas, en continua hermosura los campos, sin que el frio los marchite ni el rigor los agoste. Antes en Verano y nunca acabada Primavera son Retratos todo el año del Terrenal Paraíso: [...] ¿Qué lugar mas propio para el Paraiso que donde la hermosura la amenidad, el temple y los tiempos son siempre unos y siempre buenos? (El Paraíso... I: 38)

Sin embargo, la forma del continente hará que León Pinelo sitúe al Paraíso en la Amazonía y, más concretamente, en la selva peruana: "Herrera advierte que su figura es de un corazon humano [...]. Y si puso Dios el origen de la vida en el corazon del cuerpo; por esta semejanza pondría su principio en el corazon del Orbe $[\ldots]$ si donde suponemos el Paraiso hallamos el corazon del orbe nueba congetura es de que allí tuvo su sitio" (El Paraíso... I: 151). 
Sea como fuere, el establecimiento del Paraíso necesariamente implica una naturaleza desbordante. León Pinelo edeniza el suelo americano, lo engrandece y asegura que concentra lo mejor y más puro del planeta. La idea de la naturaleza americana como superior a la de cualquier otro territorio, se aprecia en el tercer libro de la obra, donde inicia la Historia Natural y peregrina de las Indias. El autor incluye una advertencia en la que compara a las Indias Occidentales con las Orientales:

En [las Indias Orientales] se alega que abundan de infinitas cosas peregrinas y singulares, y que por ellas merecen la primacia del Orbe, y que se entienda que donde la Naturaleza con tanta abundancia y liberalidad derramó sus thesoros y manifestó su potencia, allí estaba el Paraiso, que fué el Epitome, ó el origen de lo mejor, mas precioso, y peregrino de la Tierra. Usando ahora el mismo argumento [...], pretendemos mostrar que en ninguna de estas cosas son inferiores las Indias Occidentales, sino que en muchas se igualan, y en las demás se exceden a las Orientales. (El Paraíso... II: 3)

De esta forma, León Pinelo introduce a América en la historia mítica e imaginaria de Europa. O, más acertadamente, de esta forma las Indias ingresan en el parámetro de lo exótico y como lugar de realización de lo maravilloso.

Por otra parte, América será también el espacio en donde lo material se vea multiplicado. Dios puso en América las mayores riquezas del mundo: "la mayor grandeza y riqueza de las Indias, que es la abundancia, por no decir inmensidad, de los insignes y estimados Metales: Plata y Oro" (El Paraíso... II: 311). El contraste de la abundancia americana respecto a las cualidades atribuidas a otras latitudes, es parte de la argumentación que señala la superioridad del continente frente al resto del mundo. 
Estos intentos reafirman que León Pinelo asume un lugar de enunciación distinto al de los conquistadores y colonizadores del siglo XVI, ya que habla desde América y como americano. Este lugar de enunciación es apreciable ya en 1623, en su Discurso sobre la importancia, forma, y disposición de la Recopilación de Leyes de las Indias Occidentales. Este texto constituye una serie de recomendaciones para organizar las leyes que se han dictado para las Indias. León Pinelo concluye esta obra señalando:

Si bien es no pequeño premio el servir, como en esto sirvo, a todas las Indias, que con veinte años de asistencia tengo por Patria, si como dijo Séneca, de remed. Fortuna: Patria est, ubicumque bene est: y debiendo a ellas mi poco o mucho talento, hago lo que dijo Paulo Emilio. Patria a quae omnia accepimus, omnia redonemus. (Discurso... 176)

Arturo Andrés Roig (1986) propone que la acción de escribir de León Pinelo, entraña un potencial revolucionario en el campo de las ideas, que no ha sido considerado. Según él, El paraíso en el Nuevo Mundo desarrolla una inversión de la filosofía de la historia que existía hasta ese momento en Europa.

Las críticas al modelo centralista se pueden desarrollar, según Roig, de dos maneras. La primera, más sencilla pero menos efectiva, es negar las formas de pensamiento del centro, con esto se produce es un enfrentamiento directo con los modelos epistémicos desarrollados por las metrópolis y, por tanto, un deslinde entre el pensar periférico y la filosofía céntrica. La segunda, es la inversión que realiza León Pinelo, que consiste en desarrollar hasta el límite el pensamiento del centro para hacer que la realidad periférica calce en ella y sea capaz de invertir las lógicas: “Cómo se lleva a cabo la "inversión de la filosofía de la historia” tal como venía siendo elaborada por la cultura europea en expansión desde el siglo $\mathrm{XV}$ ? Echando mano, precisamente, de elementos teóricos y de presupuestos míticos que esa misma filosofía de la historia presentaba" (Roig 172). 
En consecuencia, el primer paso para dicha inversión es situar a América al Oriente del mundo, dejando en claro que desde nuestro continente se inició la marcha del mundo hacia el oriente. Inicia en América, se desplaza hacia el occidente hasta Asia, pasa por Europa - particularmente por España- y vuelve a contener como centro del mundo a nuestro continente, lo que genera que las Indias vuelvan a adquirir la importancia de tierra escogida que tuvieron en el inicio de los tiempos: "siempre Dios imbia sus Dones, sus favores y su noticia del Oriente, y que los hombres le debemos de buscar caminando al occidente: pues si por esta Derrota dexó Noé en prolixo castigo aquella Tierra, por la misma buelve a entrar en ella la Ley de Gracia" (El Paraíso... I: 196-197).

León Pinelo sitúa a América al Oriente -“es proposicion verdadera que el de las Yndias todo junto aunque no sea por todas sus partes, está y se debe situar al Oriente de la Asia" (El Paraíso... I: 324)-. Luego, relativiza las voces de Oriente y Occidente para cambiar el orden del mundo: "quando digo Oriente y Occidente hablo de la parte en que me nace y en que se me pone el Sol [...] el Oriente y el Occidente no son puntos fixos" (El Paraíso... I: 325).

La obra de León Pinelo logra la inversión de los parámetros epistémicos de la Europa del siglo XVII. Sin embargo, no hay que olvidar que se trata de un sujeto servicial a la corona. La investigadora Pilar Ponce Leiva señala que " $E l$ Paraíso en el Nuevo Mundo es, ante todo, una obra de alta cultura que participa del gusto barroco por lo fantástico y por lo científico a la vez. Claramente afín a los centros de poder metropolitano, León Pinelo evitó pronunciarse sobre cuestiones incómodas o polémicas" (Ponce 282).

Concordamos en que El Paraíso en el Nuevo Mundo no cuestiona directamente el poder imperial. Su enunciación es oficialista $\mathrm{y}$, por tanto, mantiene las lógicas de dominación estables en el plano político cultural, por lo demás, debido a los títulos y cargos que ostenta León Pinelo, sería extraño que fuese de otra manera. Sin embargo, la obra critica los modos de explotación de los europeos en el continente americano. Más aún, para León Pinelo, la condición peregrina del continente no ha sido debidamente estudiada $\mathrm{y}$, por consiguiente, 
España no ha cumplido las obligaciones que tiene con América: "admiro quan desobligados se hallan los Españoles de saber las cosas de las Indias, no escusandose de averiguar las de Babilonia, Egipto, Persia y Turquia, como si estas fueran mas nuestras que aquellas, y mas permitido o menos culpado ignorar lo propio que lo extraño" (El Paraíso... II: 290).

\section{III}

Simão de Vasconcellos nace en Portugal en 1597, llega en su juventud a Brasil e ingresa a la Compañía de Jesús en Bahía. En 1641 vuelve a Portugal acompañando al padre Antonio Vieira y regresa al Brasil como Provincial y rector de los Colegios Jesuíticos de Bahía y Río de Janeiro en 1642. En 1663 se imprime su Chronica da Companhia de Jesus do Estado do Brazil e do que obraram seus filhos nesta parte do novo mundo, que fue reeditada recién en 1865. Esta obra es prologada por el texto Das noticias antecedentes, curiosas e necessarias das cousas do Brasil, compuesto por dos libros publicados como volumen aparte en 1668.

Las tres ediciones del prólogo de la Chronica aparecen sin los seis parágrafos finales, que presentan la hipótesis de que el Paraíso se encuentra en la Amazonía. Éstos fueron publicados recién por el historiador brasileño Sérgio Buarque de Holanda, en la tercera edición de Visão do Paraíso.

Las Noticias de Vasconcellos, representan también la visión del pensamiento periférico, aquella que pretende recobrar, por medio de la comparación, la dignidad de los territorios degradados por el centro mediante la exaltación de la propia naturaleza, por lo tanto, el enfrentarse a ella debe hacerse mirando las cualidades específicas y particulares que tiene esta parte del mundo. Por ejemplo, el jesuita levantará una fuerte crítica contra la negación del territorio y de la posibilidad de vida, siquiera, de la América lusitana. Para ello, confronta las ideas de Aristóteles y de otros autores clásicos respecto a la zona tórrida, a la que habían calumniado: 
Por esta via pretendião os autores citados aniquilar a terra do Brasil, e da America toda, negando huns poder haver terra, onde cuidavão, que não havia Ceo. Outros negando-a por de nenhum effetto; porque debalde criaria o Autor da natureza terra que não havia de ser habitada, pela inclemencia dos astros, quando n'ella admittissemos ceo. Outros levavão esta impossibilidade pela dos mares, que tinhão por immensos, e impossiveis de navegar pera chegar a ella, caso que tal terra houvesse. E finalmente os que a concedião, era com tantas notas de inutil, inhabitavel, requeimada, etc. que era o mesmo que não haver tal terra. (Chronica..., CXIX)

En el parágrafo siguiente, Vasconcellos responde estas calumnias, asegurando que faltaría tiempo y espacio para poder eliminar todas las falsedades que pesan sobre los territorios brasileños. La edenización de la naturaleza americana, lleva a Simão de Vasconcellos a intentar sacar del error en que viven, quienes critican el territorio sin haber puesto los pies sobre su tierra (Chronica..., CXIX). Su propósito sigue siendo el principal motivo periférico, vale decir, demostrar que el propio territorio no se encuentra en desventaja, respecto a los territorios del centro, ni sus animales, ni su flora es inferior a ésta.

Durante largos fragmentos de su obra, Vasconcellos desarrollará una descripción del territorio en la que el Paraíso aparecerá constantemente, sin perjuicio de la censura inquisitorial. El objetivo común a los fragmentos en que se menciona el Paraíso, es mostrar que la tierra americana no está degradada, sino que es mejor que cualquier otra:

Sem duvida que arrependidos disserão, que a terra do Brasil, toda a America, e toda a meia Zona, a que chamavão Tórrida, não só não he terra inutil, seca, requeimada, deserta, inhabitavel pera gente humana; 
mas pelo contrario, que he huma região temperada, amena, abundante de chuvas, orvalhos, fontes, rios, pastos, verdura, arvoredos, e frutos pera perfeita habitação de viventes. [...]. Isto vemos, e gozamos nós hoje os que as habitamos, com tal suavidade de temperamento, como em hum paraiso da terra. (Chronica..., CXXI)

El tópico del clima surge en la descripción del espacio paradisiaco. Lo maravilloso debe condecirse con la perfección climática. Esto supone que no hay diferencia entre las estaciones del año, ya que su existencia es una señal de la decadencia del mundo. Por otra parte, al analizar el espacio natural, en reiteradas ocasiones Vasconcellos comparará la naturaleza de Brasil con la que rodea la imagen del Paraíso. Así, por medio de la naturaleza edenizada y de los escenarios paradisiacos, la obra insinúa el Edén al interior de Amazonía.

En las Noticias se recurre a la palabra de los teólogos antiguos, para argumentar lo favorable de la zona tórrida para la existencia humana, en donde no existiría dolor y no estaría reñida con la vida sana. Si el Paraíso está ubicado debajo de la línea equinoccial, entonces es probable que pudiese encontrarse en Brasil:

Não só os homens de nossos seculos: houve tambem muitos dos antiguos, que acertárão no conhecimento d'esta verdade. Assi o affirmavão Erathostenes, Polybio, Ptolomeo, Avicena, e não poucos de nossos Theologos, de que faz menção S. Thomas na sua Terceira parte, quest. 102 , art. $2^{\circ}$, e em tanto grão, que chegão a defender, que n'esta parte debaixo da linha equinocial criára Deos o Paraiso terrestre; por ser esta a parte do mundo mais temperada, deleitosa, e amena para a vida humana. (Chronica..., CXXI) 
Vasconcellos describirá cómo los seres humanos viven con una salud fortalecida por las condiciones propias del espacio natural. Esto resulta ser una base fundamental para su construcción paradisiaca, aunque aún no define directamente que el Paraíso se hallaba en tierras brasileñas, sino que mantiene cierta distancia y apenas lo insinúa antes de los parágrafos censurados. En cuanto a la felicidad y la salud de la que gozan los habitantes de Brasil, señala Vasconcellos:

A medida de toda a felicidade natural, foi o estado do Paraiso terreno, por isso chamado de deleites: e toda esta sua felicidade consistia no temperamento proporcionado dos quatro humores procedidos das quatro qualidades do clima; com que o homem vivêra pera sempre, e sempre com saude, e gosto; senão o impedira a amargura do peccado. D'esta medida tem descaido o genero humano; e quanto mais distante está cada qual das regiões do mundo d'aquelle clima, e temperamento primeiro, tanto mais distante está d'aquella primeira felicidade [...]. Não ha clima, nem temperamento, que não diminua d'aquelle primeiro do Paraiso: e como aquelle era a regra da vida, saude, e contentamento do homem; tudo $\mathrm{o}$ que he menos, he menos vida, menos saude, menos contentamento. (Chronica..., CXXXVIII-CXXXIX)

La obra de Vasconcellos se abre a la dimensión tan propia de un Barroco que intenta demostrar, por medio de la erudición y de la empiria, la existencia material de los temas míticos que habían sido abandonados durante el Renacimiento. Al mismo tiempo, participa de la construcción de un discurso situado que aprovecha la imagen de lo edenizado, con el fin de dar validez a la existencia misma de los territorios americanos.

La naturaleza y la fauna integran la descripción de lo paradisíaco. Así, las aves serán también un motivo para evocar al Paraíso, pues son parte de la naturaleza maravillosa de Brasil: "Todo o universo não parece vio especies, nem 
mais em numero, nem mais fermosas: parecem as mesmas dos primitivos ares, antes criadas no mesmo Paraiso da terra [...]: véja-o o leitor curioso, e compare estas com as outras aves do mundo" (Chronica..., CXLIII).

Finalmente, esta versión censurada de la obra concluirá sólo enunciando la posibilidad de que el Paraíso pueda haber estado en el continente:

Por conclusão d'este livro, e discripção do Brasil, em que temos escritto as qualidades da terra, o temperamento do clima, a frescura dos arvoredos, a variedade de plantas, e abundancia de frutos, as hervas medicinaes, a diversidade de viventes, assi nas agoas, como na terra, e aves tão peregrinas, e mais prodigios da natureza, com que o Autor d'ella enriqueceo este novo mundo: poderiamos fazer comparação, ou semelhança, de alguma parte sua; com aquelle Paraiso da terra, em que Deos nosso Senhor, como em jardim, poz a nosso primeiro pai Adam. (Chronica..., CXLVI-CXLVII)

Vasconcellos sitúa el Paraíso mediante la comparación entre el territorio y la imagen del jardín de las Delicias. Sin embargo, debido a la censura la posibilidad de situar el Edén en Brasil queda al arbitrio de los lectores, aunque no deja muchas opciones: "Deixo a seu juízo considerem a vantagem que fazem algumas terras do mundo novo aos fabulosos Campos Elysios, hortos pensiles, ilha de Atlante; e a semelhança com o melhor clima da terra, e avantajada à ilha Tapobrana, cujo clima he tão infesto à saude dos homens" (Chronica ..., CXLVII).

Los seis parágrafos censurados son rescatados y publicados recién en la tercera edición de Visão do Paraíso de Sérgio Buarque de Holanda ${ }^{3}$. Éstos corresponden al segundo libro de las Noticias Antecedentes, curiosas e necessarias, identificados con los números 105-111. En ellos, el Paraíso se ubica

\footnotetext{
${ }^{3}$ Para los efectos del presente estudio, utilizaremos la versión en castellano que publicó Biblioteca Ayacucho en su tomo La fundación de Brasil. Testimonios 1500-1700, preparado por Darcy Ribeiro y Carlos Moreira Neto.
} 
mediante la utilización del método escolástico y la cita a autoridades. Es un texto muchísimo más breve que el de León Pinelo, sin embargo, la lógica y los modelos de escritura utilizados vienen a ser similares.

Inician estos parágrafos con la ubicación del Paraíso mediante el criterio de autoridad. Se retoma la discusión respecto a lo aventajado del territorio: "Podemos agregar, que aquél lugar de la Equinoccial es templado, de abundancia de aguas, $\mathrm{y}$ frecuente de vientos que purifican los aires porque la experiencia ha mostrado que las regiones que están debajo de la zona tórrida, tenida por los antiguos como inhabitables, son templadas y se habitan con gran comodidad de los hombres" ("Noticias..." 93). Establece luego que la zona bajo la línea equinoccial es el lugar en que se encontraba el Paraíso: "pues si por todas estas excelencias la línea Equinoccial es la parte más noble del Cielo; la que corresponde en la tierra, ¿por qué no puede ser la mejor? ¿Y por consiguiente lo mejor del mundo, puerto de deleites y Paraíso Terrenal?" ("Noticias..." 94).

Dos son los problemas que enfrenta la teoría del Paraíso en América. Primero, que la línea equinoccial no sólo cruza a las Indias, sino que también recorre el mundo y divide Asia y África, por lo que el Edén podría encontrarse en esos lugares. Vasconcellos señala que en América la línea del Ecuador corta el continente medio a medio, mientras que a África sólo en un extremo próximo al Congo, en Asia sólo en distintas islas. El sacerdote niega que la patrística haya situado al Paraíso en alguno de los lugares que cruza la línea equinoccial, además, Dios tampoco "escogería partes tan fuera de las condiciones de aquel Jardín de las delicias" ("Noticias..." 95).

El segundo problema tiene relación con los ríos mencionados por la Biblia en el Génesis. Para Vasconcellos, este argumento es el reparo más importante que se puede contraponer a la idea de que el jardín del Edén se encontraría en América:

Vemos que dice la sagrada escritura que salían de la fuente de aquel hortal, de deleites cuatro Ríos, que regaban la tierra; sabemos que estos 
nacen y corren hoy por tierras que quedan al Oriente: luego en aquellas, y no en las de América está el Paraíso. Parece ésta grande fuerza, pero que se vea el Padre Soares [...] donde dice que este argumento no tiene eficacia alguna para probar la vecindad del Paraíso y muestra así porque los lugares donde brotan estos Ríos son hoy sabidos, y trillados por los hombres. ("Noticias..." 95)

A diferencia de León Pinelo, que establece que los ríos en realidad son otros a los que las Escrituras habrían cambiado el nombre (El Paraíso... II: 431), Vasconcellos pone en duda que la ubicación de los ríos sea un argumento válido para situar al Paraíso. El que se haya subido a las fuentes de estos ríos y que no se haya encontrado el Edén, prueba que se encuentra en otro lado y conectado con estos ríos mediantes fuentes subterráneas e irreconocibles para los seres humanos. Por lo que las fuentes podrían estar en áreas bastante alejadas del oriente, por ejemplo, en América.

Zulmira Santos (2001), explica la obra de Vasconcellos señalando que la importancia del Paraíso radica en el deslumbramiento frente al mundo natural:

Citando a Sagrada Escritura, no Capítulo I do Génesis, Vasconcellos sublinha que para que uma terra tenha o nome de boa deve obedecer a quatro requisitos -"que se vista de verde"; "que goze de bom clima"; “que sejam suas águas abundantes de peixes, e seus ares abundantes de aves"; "que produza todos os gêneros de animais e bestas da terra"- os quais são, justamente, cumpridos na íntegra pelos territórios de VeraCruz [...]. O autor deixa-se, assim, seduzir pela quantidade de "verde" perene, essa cor simbólica da harmonia da natureza que caracteriza a paisagem brasileira. (Santos 158) 
La tierra a la que se enfrenta Vasconcellos cumple con todos los requisitos para poder llamarse una buena tierra. Pero por qué ubica al Paraíso en Brasil. Santos señala que el sacerdote se opone a lo que se ha llamado la "guerra justa" contra los indios, por lo que en su Crónica inventaría las condiciones que llevan a los indígenas a levantarse contra los portugueses (Santos 169). Esta discusión tiene un componente altamente mítico en Brasil, y para Vasconcellos se vuelve un problema de la Compañía de Jesús, por lo cual la imagen del Paraíso corresponde, también, con el aporte que puede hacer para mantener el dominio de los jesuitas, por sobre el del poder imperial. Esto es evidente en las preocupaciones que tiene el sacerdote, para poder evidenciar el trabajo de la Compañía en Brasil: "Lado a lado com as preocupações com a liberdade dos indígenas a Chronica relata, com alguma insistência, as atividades educativas e catequéticas, desde a fundação de colégios e confrarias, às escolas de doutrina cristã que privilegiavam o ensino das crianças encarando-as como o melhor meio de chegar aos adultos" (Santos 172).

Al igual que León Pinelo, Vasconcellos asume su lugar de enunciación desde América, se siente parte del territorio. Pese a la omisión y pocas noticias entregadas sobre los indígenas, las Noticias se presentan como una alabanza al continente.

Vasconcellos no llega a invertir la filosofía de la historia, como lo hiciese León Pinelo. Sin embargo, ambos autores plantean un discurso situado en América, lo que significa un quiebre en la perspectiva de enunciación con los navegantes del siglo XVI. Así, aunque no es un pensamiento abiertamente contrario a los poderes imperiales, ni siquiera es una franca oposición abierta, ambos autores son europeos que asumen una perspectiva americana para plantear un discurso dignificante del territorio, de su naturaleza y, en el caso de Vasconcellos, de sus habitantes. 
CATEDRAL Tomada: Revista literaria latinoamericana / Journal of Latin American Literary Criticism Pablo Hurtado Ruiz

\section{Bibliografía}

Abramo, Nicolao. Pharus Veteris Testamenti, sive sacrarum quaestionum libri $X V$. Quibus accesserunt ejusdem auctoris de veritate et mendacio libri IV. Paris: Sumptibus Ioannis Iost, via Iacoæa, sub signo Sancti Spiritus, 1648. Disponible en: https://archive.org/details/bub gb RPEUySto3WoC

Acosta, Joseph. Historia natural y moral de las Indias. México D.F.: Fondo de Cultura Económica, 2006.

Colón, Cristóbal. Textos y documentos completos (Edición de Consuelo Varela). Nuevas cartas (Edición de Juan Gil). Madrid: Alianza Editorial, 1995.

Devés, Eduardo. Pensamiento periférico. Asia-África-América Latina-Eurasia y algo más. Una tesis interpretativa global. Buenos Aires: CLACSO / IDEAUSACH, 2014.

Herrera, Antonio de. Historia general de los hechos de los castellanos en las islas i tierra firme del mar oceano. Madrid: Imprenta real de Nicolas Rodiquez Franco, 1730. Disponible en:

https://archive.org/details/generaldehechosd01herr

Lapide, Cornelii A. Comentarii in Sacram Scripturam. (Tomus I). Lyon: Ex typis Pelagaud et Lesne, 1840. Disponible en:

https://archive.org/details/commentariiinsac01lapi

León Pinelo, Antonio. El Paraíso en el Nuevo Mundo (Edición de Raúl Porras Barrenechea). Lima: Comité del IV centenario del descubrimiento del Amazonas, 1943.

---. Discurso sobre la importancia, forma, y disposición de la Recopilación de Leyes de las Indias Occidentales que en su Real Consejo presenta el Licenciado... 1623. Santiago: Fondo Histórico y Bibliográfico José Toribio Medina, 1956.

López de Gómara, Francisco. Historia general de las Indias y Vida de Hernán Cortés. Caracas: Biblioteca Ayacucho, 1979. 
CATEDRAL Tomada: Revista de crítica literaria latinoamericana / Journal of Latin American Literary Criticism El Paraíso terrenal en la América del siglo XVII: Antonio de León Pinelo y Simão de Vasconcellos.

Maluenda, Tomás. De paradiso volvptatis qvem Scriptvra Sacra Genesis secvndo et tertio capite describit. Commentarius. Roma: Ex typographia Alfonfi Ciacconi Apud Carolum Vulliettum, 1605. Disponible en:

https://babel.hathitrust.org/cgi/pt?id=ucm.5323595253; view=1up;seq=5;siz $\underline{\mathrm{e}=125}$

Medina, José Toribio. Historia del Tribunal del Santo Oficio de la Inquisición de Lima. Santiago: Fondo Histórico y Bibliográfico José Toribio Medina, 1956.

Montesinos, Fernando de. Avto de fe celebrado en Lima a 23 de enero de 1639. Al Tribunal del Santo Oficio de la Inquisicion de los Reynos del Peru, Chile, Paraguay y Tucuman. Lima: Impreso por Pedro Cabrera, 1639. Disponible en: https://archive.org/details/autodelafecelebr00trib

Pellicer, Rosa. “Continens Paradisi: el libro segundo de El Paraíso en el Nuevo Mundo de Antonio de León Pinelo". América sin Nombre 13-14 (2009): 3036.

Ponce Leiva, Pilar. "Visiones del Paraíso. Erudición y denuncia social entre la Amazonía y los Andes a fines del siglo XVII". Chronica Nova 39 (2013): 275-290.

Porras Barrenechea, Raúl. "Don Antonio de León Pinelo (1596-1660) y su obra El Paraíso en el Nuevo Mundo (1650)". Antonio de León Pinelo. El Paraíso en el Nuevo Mundo. Lima: Comité del IV centenario del descubrimiento del Amazonas, 1943.

Roig, Arturo Andrés. “La 'inversión de la filosofía de la historia' en el pensamiento latinoamericano". Revista de filosofía y teoría política 26-27 (1986): 170-174.

Santos, Zulmira. "Em busca do paraíso perdido: a Chronica da Companhia de Jesu do Estado do Brasil de Simão de Vasconcellos, S.J.”. José Adriano de Freitas Carvalho. Quando os frades faziam história: de Marcos de Lisboa a Simão de Vasconcellos. Porto: Universidade de Porto, 2001. 145-178. 
Solórzano, Juan. De indiarum iure. (Liber I: de Inquisitione Indiarum). Madrid:

Consejo superior de investigaciones científicas, 2001.

Vasconcellos, Simão. Chronica da Companhia de Jesus do Estado do Brazil e do que obraram seus filhos nesta parte do novo mundo. Em que se trata da entrada da Companhia de Jesu nas partes do Brasil, dos fundamentos que n'ellas lançaram e continuaram seus religiosos, e algunas noticias antecedentes, curiosas e necessarias das cousas d'aquelle estado. Lisboa: Em casa do Editor A. J. Fernandes Lopes, 1865.

---. "Noticias curiosas y necesarias". En La fundación de Brasil. Testimonios 1500-1700. Caracas: Biblioteca Ayacucho, 1992. 92-96. 